\title{
O MEDO: EXPRESSÃO DE UM COLETIVO DE TRABALHADORES
}

http://dx.doi.org/10.1590/1984-0292/1238

\author{
Andréa Luiza da Silveira, Álvaro Roberto Crespo Merlo ${ }^{\star}$ \\ Universidade Federal do Rio Grande do Sul, Porto Alegre, RS, Brasil
}

\section{Resumo}

Objetivou-se analisar a condição de possibilidade da experiência do medo relacionada à solidariedade e à resistência. Articulou-se a história do coletivo de trabalhadores dos frigorificos da região oeste catarinense, enfatizando a constituição da gestão flexivel a partir da década de 1990 e o processo de luta por uma representação sindical legítima, integrando poder público e movimentos sociais. Utilizou-se a pesquisa bibliográfica e documental e a pesquisa participante, mediante a vivencia dos autores em atividades promovidas pelo sindicato da categoria. As análises, por um lado, resultaram no entendimento de que a luta dos trabalhadores dos frigoríficos da região de Chapecó (SC) ocorreu, sobretudo, pelo controle do processo de trabalho, isto é, a normatização do ritmo, da jornada, das pausas e da temperatura; e, por outro lado, mostraram que o medo, como palavra referida recorrentemente, expressa certa relação com o futuro como de possibilidades mortas, apontando para novas investigações que contemplem quadros psicopatológicos.

Palavras-chave: medo; psicologia do trabalho; existencialismo moderno; psicodinâmica do trabalho; psicopatologia.

\section{The FEAR: WORKERs COLLECTIVENESS EXPRESSION}

\section{Abstract}

The aim was to analyze the possible condition of fear experienced regarding to solidarity and to resistance. The collectiveness history of meat plants workers from the Western region of Santa Catarina State was reviewed emphasizing the 90's flexible management style, and their fight process for legitimate labor union representativeness, integrating the public sector and social movements. Bibliographical and documental research was carried out along with participative research, on behalf of the authors experience on activities promoted by this labor union. The analysis resulted, on one hand, on the understanding that the struggle of the meat plant workers of Chapecó region / SC was mainly for controlling of the work process, i.e., the normalization of the working hours, the shifts, breaks and room temperature. And on the other hand, this research showed that the word fear repeatedly, expresses a certain relation with their future death possibilities, indicating the need of further investigations comprising psychopathology.

\footnotetext{
^Endereço para correspondência: Universidade Federal do Rio Grande do Sul, Faculdade de Medicina, Departamento de Medicina Social. Rua Ramiro Barcelos, 2600 - $4^{\circ}$ andar - Santana. 90035003 - Porto Alegre, RS - Brasil.E-mail: deasilveira@gmail.com, merlo@ufrgs.br
} 
Keywords: fear; work psychology; modern existentialism; psychodynamic work; psychopathology.

\section{INTRODUÇão}

A questão aqui proposta pretende transitar pelos campos da psicologia social e do trabalho, num horizonte crítico. A psicologia social do trabalho tem como um dos seus desdobramentos metodológicos abarcar o universo da ação humana envolvendo a relação do sujeito com os outros e consigo mesmo, com a matéria (concreta ou abstrata) e sua organização no mundo. Ela constitui, deste modo, uma história que é marcada por uma temporalidade passada e por um porvir. Objetivamos analisar, a partir desses preceitos, algumas das dimensões que compõem a disputa pelo controle do processo de trabalho e seus atravessamentos no âmbito da experiência psicológica, utilizando como recorte o emprego da palavra "medo" por trabalhadores de frigoríficos.

Participamos de algumas atividades organizadas pelo sindicato da categoria, a saber: a) o acompanhamento da efetivação do Termo de Ajuste de Conduta (TAC) n. 01477/2011, através de reuniões da diretoria de sindicato e trabalhadores; b) da elaboração de um projeto desenvolvido por diretores do sindicato e pesquisadores, entre os quais os autores deste artigo, destinado à potencialização do controle social da saúde do trabalhador que buscou o financiamento do Ministério Público do Trabalho em função das multas impetradas à época à Sadia S.A.; c) do I Seminário de Saúde do Trabalhador de Abate e Beneficiamento de Carnes do Oeste Catarinense, em 2012; d) o processo de votação em assembleia do estado de greve, também em 2012; e) do II Seminário de Saúde do Trabalhador de Abate e Beneficiamento de Carnes do Oeste Catarinense, em 2013; f) das discussões sobre a Norma Regulamentadora n. 36 - Segurança e Saúde no Trabalho em Empresas de Abate e Processamento de Carnes e Derivados -, que foi publicada no Diário Oficial em 2013; e g) da devolutiva à diretoria do sindicato da produção textual apresentada, pelos autores, no Congresso da Associação Latino-Americana dos Estudos do Trabalho (ALAST), em 2013.

O acompanhamento dessas atividades envolveu inicialmente um esforço bastante expressivo direcionado ao entendimento dos contextos histórico e social, resgatando a história da agroindústria. Assim, constatamos certas particularidades do modelo de gestão flexível que foi adotado no setor somente a partir da década de 1990, rompendo com o patriarcalismo que lhe era característico. Notamos também que, no campo das lutas políticas, a disputa por uma representação sindical eleita democraticamente, que culminou na eleição da atual diretoria, em 2010, integrou o movimento dos trabalhadores, o poder público e os movimentos sociais contra a antiga diretoria - esta recorria ao regimento interno, o qual estipulava que, havendo troca de parte da diretoria, as eleições não eram necessárias. Durante 22 anos, a diretoria do sindicato representante da categoria dos trabalhadores de abate e beneficiamento de carnes foi composta por pessoas ligadas às 
duas principais indústrias frigoríficas da cidade: Aurora Alimentos e Sadia S.A. - esta, depois da fusão com a Perdigão, efetivada em 2011, após dois anos de negociação, tornou-se Brasil Foods S.A.

A partir da gestão da diretoria sindical, eleita em 2010, algumas lutas tornaram-se possíveis. Destaca-se, então, ainda no campo político, o processo de trabalho como locus de embate, sobretudo no que se refere à definição do ritmo, da jornada, das pausas e da temperatura. Tal assertiva foi constatada tanto nas discussões que implicaram o acompanhamento do TAC/2011 quanto nas negociações que envolveram a Norma Regulamentadora 36 (NR-36), publicada em 2013. Isso porque ambos os documentos normalizam aspectos do tempo de trabalho, ou seja, jornada, horas-extras, pausas e ritmo, e aspectos das condições de trabalho, isto é, temperatura e ruído. Alguns trabalhadores conheciam as normas que a organização tinha se comprometido a seguir e observaram que eram burladas no cotidiano do trabalho. Notou-se a experiência psicológica manifestada pela palavra "medo", denotando o vivido por trabalhadores e dirigentes sindicais ligado ao sofrimento decorrente do trabalho, como também à construção de formas de resistência.

Benjamin (1994) faz a interessante comparação entre o trabalho do artesão, relacionando-o à narrativa, e o trabalho fragmentado moderno, permeado pela perda da narrativa, isto é, do contar histórias. Ele mostra como a narração combinava-se ao trabalho artesanal do camponês, dos marinheiros e dos artífices.

A alma, o olho e a mão estão assim, inscritos no mesmo campo. Interagindo, eles definem uma prática. Essa prática deixou de nos ser familiar e o papel da mão no trabalho produtivo tornou-se mais modesto, e o lugar que ela ocupava durante a narração está agora vazio. (BENJAMIN, 1994, p. 220).

Assim, a narração implicava contar uma história também com as mãos, expressando a experiência do locutor e do ouvinte. Esta característica do trabalhador artesanal no molde pré-capitalista, quando o trabalhador utilizava-se das mãos, de acordo com Benjamin, está perdida no capitalismo moderno com sua linha de produção, na qual o trabalhador utiliza-se da "mão" e do "olho" imitando as marionetes do titereiro.

Alguns autores, como Bondía (2002), afirmam que o trabalho não é mais um lugar da experiência e tampouco da narrativa. O pesquisador espanhol define a experiência, juntamente com Benjamin (1994) e Heidegger (2003), como algo que nos toma, se passa conosco, nos toca ou nos acontece. Demarca, ainda, que a palavra "[...] tem a ver com [...] o modo como nos colocamos diante de nós mesmos, diante dos outros e diante do mundo em que vivemos." (BONDÍA, 2002, p. 20). Afinal, a linguagem não tem no trabalho o mesmo lugar que tem na poesia ou para o ofício do poeta como quer Heidegger (2003). Assim perguntamo-nos: "qual o seu lugar no trabalho?" 
Entendemos que o trabalho é lugar de experiência, quer em sua perspectiva coletiva, quer em sua dimensão individual. Entretanto, se não há lugar, no trabalho, para uma narrativa tal qual a concebe Benjamin, há o lugar da fala e do silêncio, como Dejours (DEJOURS; BÈGUE, 2010) tem nos ensinado. Seguimos, no entanto, com Adorno (2003, p. 26), na sua concepção de que "A relação com a experiência [...] é uma relação com toda a história [...]"; exatamente neste quesito de que a experiência individual faz parte, ao mesmo tempo, da história local e da história de toda a humanidade. Neste sentido, a palavra, como nos instiga Sartre $(1997,2002)$ a pensar, pode nos direcionar a uma situação específica e a seu contexto geral.

\section{ConsolidaÇão da reestruturaÇão produtiva na Agroindústria do Oeste Catarinense}

A instalação da agroindústria no Oeste catarinense, em meados da década de 1950, é marcada pela inserção social da família Fontana na comunidade. O patriarca Atílio Fontana recrutava os trabalhadores entre amigos, vizinhos e parentes. Havia também um conjunto de forças políticas organizando-se na região, a fim de produzir as condições infraestruturais necessárias para a instalação da agroindústria. Assim, mobilizavam-se as forças populares, sobretudo promovendo o orgulho de se ter uma indústria importante na região, bem como o orgulho de ser participante dessa força de trabalho (ESPÍNDOLA, 1999; SANTOS, 2011).

Em associação ao crescimento da agroindústria, tem-se que as terras disponíveis para a atividade agrícola tornam-se mais escassas. As pequenas propriedades passam a ser divididas pelos membros das famílias, deixando de fora os meeiros, que se tornam recursos humanos para a agroindústria nascente. Muitas dessas propriedades passam a ser utilizadas para o plantio de cereais destinados a alimentar os animais para o abate (SANTOS, 2011; ESPÍNDOLA, 1999). Deste modo, engendra-se a condição daqueles trabalhadores que são chamados de "integrados", isto é, os criadores que integram uma determinada empresa de abate e beneficiamento de carnes, no entanto, sem vínculo empregatício. Tais fatos configuram-se como determinantes para a precarização da agricultura, aliada à crença dos trabalhadores de que a agroindústria traria crescimento econômico, tanto para eles quanto para a região.

Espíndola (1999) e Santos (2011) sugerem, ao mobilizarem a história da agroindústria, que o crescimento almejado ocorreu parcialmente. A pesquisadora mostra como se engendra nos trabalhadores o orgulho de ser funcionário da antiga Sadia S.A., atualmente Brasil Foods, que consistia em ter crédito na praça, ter a credibilidade das outras pessoas da cidade, a melhoria efetiva das condições materiais de vida - além disso, o trabalho no frigorífico era considerado melhor em relação àquele realizado na agricultura. A literatura apresenta (SANTOS, 2011; ESPÍNDOLA, 1999) um incipiente movimento por melhores condições de trabalho e saúde ao mesmo tempo que, nas relações sociais e afetivas entre os trabalhadores e seus gestores, predominavam as experiências psicológicas decorrentes do orgulho de ser trabalhador dessa empresa. 
O processo histórico caracteriza-se, primordialmente, pela substituição gradual do trabalho semiartesanal dos frigoríficos surgidos na região Oeste catarinense, em meados dos anos 1950, pelo trabalho industrial. Torna-se relevante para a nossa análise o fato de que as expressões tenham se alterado, isto é, do "orgulho" do trabalho próximo ao artesanal e de uma linha de produção taylorista mais pesada e mais lenta para o "medo", que nos arvoramos a julgar como uma expressão típica inserida nos contextos que permeiam a relação entre capital e trabalho no mundo moderno.

As analogias de Benjamin nos auxiliam a argumentar que no trabalho semiartesanal a alma, o olho e a mão estavam em maior harmonia, simbolizada pelo "orgulho" de ser trabalhador do frigorífico. O trabalho da linha de produção taylorista, por sua vez, contava com uma gestão patriarcal, cujos agentes mantinham uma relação com as comunidades às quais pertenciam os trabalhadores, onde ocorriam as festas comunitárias, os jogos de futebol, etc. E, ainda de outro modo, as comunidades participavam da empresa através das festividades de final de ano e em datas específicas. Atualmente, porém, é o "medo" que expressa a vivência da alma sequestrada do corpo, reduzindo o trabalhador apenas à mão e ao olho.

A partir da década de 1990, a gestão patriarcal e a maquinaria pesada, típicas do taylorismo e do fordismo, vão cedendo espaço, aos poucos, para o modelo de gestão flexível e sua maquinaria leve e rápida (ESPÍNDOLA, 1999; SANTOS, 2011). Neste universo da gestão flexível e "moderna" é que a experiência psicológica de "orgulho" vai diminuindo e outras experiências vão surgindo e se afirmando, tal como a experiência do "medo".

O "medo" e o "orgulho" têm em comum a mesma dimensão ontológica, isto é, em que o sujeito se experimenta reconhecendo para si mesmo o olhar do outro sobre ele - tal como a "vergonha", exemplo utilizado por Sartre (1997, p. 290) para explicar o reconhecimento, isto é, "Reconheço que sou como o outro me vê". Entretanto, ainda de acordo com Sartre (1997), esta experiência, resgatada pela reflexão, pode ser vivida sem ser conhecida. Entre as contribuições do pensamento de Sartre, trata-se de diferenciar o saber do conhecer. Nestes termos, não podemos nos enganar a respeito do "medo", do "orgulho" ou da "vergonha" que sentimos, mas podemos vivê-los, sabendo-os, sem, portanto, conhecê-los. Isso nos leva a crer que a maioria dos trabalhadores vive o "medo", ou seja, aquilo que é vivido é sabido sem, no entanto, ser conhecido, sobretudo no que se refere às circunstancias sócio-históricas.

Utilizaremos como exemplo as negociações da data base de 2012 para ilustrar a diferenciação entre o "saber", o "conhecer" e o "medo". As pautas de negociação são votadas por empresas. Neste caso, nosso exemplo se refere à negociação da data base dos trabalhadores da Sadia S.A. Inicialmente, gestores representantes da Sadia S.A. e direção sindical encontraram-se e, na oportunidade, foi esclarecida a proposta da empresa para o aumento salarial, que, depois de ser levada aos trabalhadores por sua diretoria, foi rejeitada. Tal proposta consistia num aumento salarial por metas, ou seja, mérito e enquadramento de cada trabalhador. Entre os pontos de reivindicação constavam também aqueles sobre 
a saúde, especificamente sobre o tempo de trabalho e as condições de trabalho. Estas especificamente: a) as cinco pausas de oito minutos durante a jornada de trabalho; b) o ritmo de trabalho e outros pontos previstos no TAC/2011 (SITRACARNES, Boletim 13, 2012). Ressaltamos ainda as cláusulas das reivindicações dos trabalhadores sobre saúde:

Que a empresa aceite todos os atestados médicos, inclusive da rede pública, não apenas os concedidos pelos médicos conveniados; Que o empregado opte em participar ou não do convênio, sem que haja limites de consulta; A empresa deve dar condições de readaptação aos trabalhadores acidentados ou com doenças ocupacionais no retorno deste; A empresa deve pagar a diferença salarial aos trabalhadores afastados pelo INSS e contratar um novo trabalhador para substituir o afastado; Diminuição do ritmo de trabalho; Pausa de 10 minutos a cada 50 minutos trabalhados. (SITRACARNES, Boletim 12, 2012).

As negociações entre sindicato e Sadia S.A. acirraram-se, resultando em certos impasses e forçando o sindicato a propor o estado de greve que foi votado em assembleia no dia 30 de julho de 2012. A assembleia ocorreu no pátio da principal unidade da empresa em Chapecó (SC). As dificuldades de negociação residiam em discordâncias sobre as não conformidades do processo de trabalho, entre elas a duração da jornada e o ritmo - que extrapolavam os limites impostos pelo TAC/2011, além de serem comprovadamente danosos - e os problemas dos trabalhadores referentes aos atestados médicos - em função de os médicos da empresa só aceitarem os atestados emitidos pelos médicos conveniados com a empresa (SITRACARNES, Boletim 16, 2012), o que tornava possível que ainda mais trabalhadores exercessem suas atividades com dores e utilizando-se de anti-inflamatórios e analgésicos.

Nesse evento, a direção da Sadia S.A. conduziu os trabalhadores até o local da assembleia em fila indiana e tendo à frente gestores e líderes de equipes. Foi registrado no Boletim 19 (SITRACARNES, 2012) que apenas 2.400 trabalhadores, que correspondem a $40 \%$ do total da população trabalhadora dessa unidade, participaram da assembleia. Destes, somente 1.955 trabalhadores votaram. É importante ressaltar que, na semana que precedeu a votação do estado de greve, 30 trabalhadores foram demitidos e muitos outros pressionados. Decorreu que o resultado da votação foi desfavorável ao estado de greve, isso porque o "O voto foi secreto mas mesmo assim muitos trabalhadores ficaram com medo." (SITRACARNES, Boletim 19, 2012).

Esse relato parece ser um dos elementos que podem contribuir para a compreensão mais acertada sobre o sentido do "medo". Ele pressupõe o conhecido e o sabido sobre a condição do trabalhador e da própria agroindústria. Esta, que requer mão de obra - há um índice de rotatividade e absenteísmo que preocupa o Departamento de Recursos Humanos da empresa -, faz ameaças constantes de demissão engendrando a experiência do "medo". Desta forma, para 
Merleau-Ponty (2012, p. 33), os significados precisam ser entendidos na “[...] sua configuração social, num espaço e num tempo sociais, conforme um código social e, finalmente, antes como símbolos do que como causas." A experiência do "medo", então, no seu aspecto simbólico, apresenta-nos o que Sartre (1997, 2002) denomina de "possibilidades mortas". Assim, embora sejam muitas as variáveis que constituem tal fenômeno social no seu genuíno ocorrer, optamos por abstrair dessa situação complexa o "medo" como palavra que nos leva a algo que acontece, isto é, a uma experiência.

A palavra em si carrega um significado à medida que a encontramos na torrente da linguagem. Portanto, o significado só pode ser desvelado, de fato, em situação. Merleau-Ponty (1991, p. 86) postula que "O fato é que a linguagem não poderia proporcionar a própria coisa a não ser que deixasse de estar no tempo e na situação." Sartre (1997) corrobora ao considerar que o sentido da palavra somente pode ser compreendido em situação, isto é, no contexto a que se refere. A palavra nos remete à situação; e esta, às condições históricas de possibilidade do sentido daquela palavra. Sartre (1997, p. 632) escreve:

Compreender a palavra à luz da frase é exatamente compreender qualquer que seja o dado a partir da situação [...] a linguagem falada, sempre é decifrada a partir da situação. As referências ao tempo, à hora, ao lugar, aos arredores, à situação da cidade, da província ou do país aparecem antes da palavra.

Para os fins de nossa análise, o "medo" como palavra expressa aspectos da vivência de um coletivo de trabalhadores aparecendo depois da situação, que foi se constituindo a partir de um processo histórico. Neste caso específico, tal processo histórico consolida-se nos anos 1990, quando o modelo de gestão flexível foi sendo adotado pelos herdeiros de um dos idealizadores da agroindústria da região Oeste de Santa Catarina (SANTOS, 2011), dando origem à Sadia S.A. Apontamos, então, que existe a forte possibilidade de que o "medo" esteja relacionado ao modelo de gestão flexível e de que, nos últimos anos, esteja sendo utilizado como mecanismo de gestão.

\section{O "MEDO" COMO “POSSIBILIDADES MORTAS" E A EXPERIÊNCIA DO CORPO MÁQUINA}

O atual contexto da vivência do "medo" é marcado por certa "vitória" dos trabalhadores. Em 2010 completaram-se 22 anos de uma hegemonia sindical que servia aos interesses dos principais frigoríficos da região, rompida pela eleição da atual diretoria. Faz-se importante enfatizar que nesse processo eleitoral configuraram-se forças de resistência para tornar tal eleição possível. Entre os eventos mais relevantes está a solicitação feita pelo Ministério Público do Trabalho da região ao Ministério do Trabalho e Emprego (MTE) para a verificação das condições de trabalho a que os trabalhadores estavam sujeitos na maior indústria da região, a Sadia S.A. O trabalho do MTE resultou na identificação de não conformidades no processo de trabalho, fundamentando o nexo do adoecimento dos trabalhadores 
com as atividades laborais e oferecendo as bases necessárias para uma Ação Civil Pública, impetrada pelo Ministério Público do Trabalho (SARDÁ; RUIZ; KIRTSCHIG, 2009), que baseou, em 2011 um Termo de Ajuste de Conduta - TAC.

Sardá, Ruiz e Kirtschig (2009) mostraram alguns dados oferecidos pelo Procedimento de Investigação do Ministério Público do Trabalho (MPT) - Ofício de Chapecó e pela Gerência Executiva do Instituto Nacional do Seguro Social (INSS) da mesma cidade. A análise dos dados revelou, nesta oportunidade, "uma elevada prevalência e incidência crescente de doenças e agravos à saúde, especialmente relacionadas a distúrbios osteomusculares e transtornos mentais [...]" (SARDÁ; RUIZ; KIRTSCHIG, 2009, p. 61).

Numa reunião do sindicato que visou, sobretudo, acompanhar a implementação das exigências estabelecidas pelo TAC/2011 numa das unidades dessa empresa, ao tratar-se do item c. - "Proceder às notificações de todos os acidentes de trabalho [...]" (BRASIL, 2011, p. 2) -, os trabalhadores presentes relataram que as notificações não estão sendo realizadas pela empresa e que se submetem a tal situação porque têm medo. O TAC/2011, à época, consistia num recurso que os trabalhadores tinham para fazer valer seus argumentos sobre o ritmo excessivo ou a temperatura muito baixa do ambiente etc. Entretanto, tem-se hoje a NR-36 (BRASIL, 2013), que estabelece, principalmente, os critérios para ritmo, temperatura, jornada e ruído, de forma semelhante às normas previstas pelo TAC/2011. Mas, ainda assim, no cotidiano de trabalho na fábrica, a gestão continua lançando mão dos seus mecanismos de dominação, desconsiderando, inclusive, as regras sobre a organização do processo de trabalho que a própria agroindústria colaborou para estabelecer através do processo de negociação que resultou na NR-36. Assim, asseveramos que a manipulação do medo passa a ser um dispositivo de gestão, que, ao contribuir para fragmentar a solidariedade desse coletivo de trabalhadores, afeta as condições de possibilidade tanto de resistir quanto de considerar a manutenção das conformidades adequadas do processo de trabalho como um direito legítimo.

$\mathrm{Na}$ arqueologia das ciências humanas, Foucault (1987a, p. 117) nos mostra a condição de possibilidade dessas "ciências", no período que marca a transição do classicismo para a modernidade, assinalando que as instituições modernas como a prisão, o hospital e a escola consolidam-se também por "[...] uma descoberta do corpo como objeto e alvo de poder". O corpo passa a ser disciplinado numa junção entre docilidade e utilidade promovida no interior das instituições.

A fábrica, à qual o trabalho artesanal deu lugar, é a instituição moderna onde o trabalho operário é dominado através da disciplina, como a retrata o autor francês: "[...] o espaço das disciplinas é sempre, no fundo, celular. Solidão necessária do corpo e da alma [...]" (FOUCAULT, 1987a, p. 123). O exercício dos métodos de adestramento viabiliza tal solidão à medida que os corpos são dispostos em sequência e classificados de acordo com sua utilidade.

Foucault (1987a, p. 125) definiu a disciplina na fábrica como “[...] a arte de dispor em fila, e da técnica para a transformação dos arranjos. Ela individualiza os corpos por uma localização que não os implanta, mas os distribui e 
os faz circular numa rede de relações." A arqueologia do poder permitiu-o vislumbrar a alma e o corpo modernos como objeto de dominação do saber/poder (SILVEIRA; FURLAN, 2003).

Foucault (1987b) investiga a função do olhar hierárquico, da sanção normalizadora e do exame, que nas fábricas correm ao longo de todo o processo de trabalho. Destacamos a vigilância, pois ela ocupa um espaço de grande funcionalidade no que diz respeito ao trabalho. "Vigiar torna-se então uma função definida, mas deve fazer parte integrante do processo de produção; deve duplicá-lo em todo o seu comprimento. Um pessoal especializado torna-se indispensável, constantemente presente, e distinto dos operários." (FOUCAULT, 1987a, p. 146). No caso específico do qual tratamos, temos, por um lado, os trabalhadores especializados, ou seja, administradores, psicólogos, médicos, engenheiros e enfermeiros; por outro lado, os trabalhadores da linha de produção especializados em vigilância, em geral, promovidos a esta função: os líderes e os encarregados.

O exame "[...] supõe um mecanismo que liga certo tipo de formação de saber a certa forma de exercício de poder" (FOUCAULT, 1987a, p. 156), que implica a especialização técnico-científica, como podemos vislumbrar sobre os trabalhadores da saúde na Sadia S.A. e a rede que constituem manipulando, por exemplo, os atestados médicos e as notificações de acidentes de trabalho. Porém, a rede de relações entre os agentes que compõem a média gerência, isto é, líderes e encarregados, garante que os trabalhadores "doentes" ou queixosos sejam levados a "julgamento", sobretudo pelos profissionais da saúde e da assistência da empresa. Eventualmente, tal rede de profissionais dá início ou continuidade a um processo que leva ao diagnóstico de alguma "doença", seja ela física ou mental (DAL MAGRO, 2012). A psicologia, no tocante à doença mental, tem ratificado o discurso psiquiátrico. Aparentemente esta ciência renuncia da sua capacidade de relacionar as condições gerais de vida e de trabalho à experiência psicológica que nos remete a toda a história. Faz o papel, por fim, de agente que promove a culpabilização do sujeito pelo sofrimento, pela doença ou pelo acidente (SELIGMANN-SILVA, 2011).

Nos contextos de trabalho, em particular, é mediante a queixa de sofrimento físico que o trabalhador expressa seu sofrimento para a sua rede social da fábrica, constituída pelos seus pares e pela média gerência (SELIGMAN-SILVA, 2011). E parece que, deste modo, um "diagnóstico" se inicia. Por conseguinte, consideramos que a partir da análise de tal fato podemos conceber que também no âmbito do trabalho

[...] o corpo é um elemento sobre o qual inúmeras correlações de forças incidem e se dispõem, atravessando-o e exercendo sobre ele uma série de conformações, dentro de um jogo de dominações e submissões, difuso e disperso em toda a rede social (SILVEIRA; FURLAN, 2003, p. 187). 
Utilizaremos como exemplo o I Seminário de Saúde do Trabalhador, organizado pelo sindicato da categoria de Chapecó, em 2012, cujos temas prioritários giraram em torno das questões sobre a organização política dos trabalhadores e sua relação com a organização do trabalho. Alguns trabalhadores se manifestaram, e três falas nos pareceram emblemáticas. Uma delas revelou que "[...] nós somos as máquinas que tocam a empresa. São poucos que ganham pra todo mundo sofrer." A outra referiu que "[...] a máquina é o patrão que a gente tem que acompanhar." E, ainda outra fala que nos confirmou nas nossas análise, expressou que "[...] as pessoas estão doentes porque não encontram outras saídas". Estas falas sugerem um universo de contradições e conflitos presentes numa multiplicidade de situações que desenham as experiências dos trabalhadores nos ditos frigoríficos. Elas indicam o que chamamos de "possibilidades mortas", isto é, experiências tais em que o futuro apresenta-se como roubado, pois se perde o controle sobre a sua própria história, vivenciando-se, por exemplo, como parte da máquina. Neste sentido, Sartre (1997, p. 73) assevera que

[...] a angústia distingue-se do medo porque medo é medo dos seres do mundo, e angústia é angústia diante de mim mesmo. [...] Uma situação que provoca medo, pois ameaça modificar de fora minha vida e meu ser, provoca angústia na medida em que desconfio de minhas reações adequadas a ela.

Sartre (1997), no seu tratado de ontologia, desenvolve seus conceitos em níveis elevados de abstração, isto é, não realiza na oportunidade a análise de um contexto específico. A nossa análise, de outro modo, parte de situações em que o uso da palavra "medo" foi recorrente. A palavra "medo" liga-se, segundo nossa análise, ao campo de possibilidades de sua ocorrência. Entendemos, assim, fazendo uso de recursos teóricos e metodológicos dos quais dispomos, que neste caso específico o "medo" sucede diante das "possibilidades mortas", ou, de outro modo, mediante certa experiência que remete a uma "reificação" evidenciada pela vivência de ser parte da máquina, pois a máquina não deseja e não se dá um futuro.

Ao examinarmos as repercussões profundas em que o "medo" é vivido, entendemos que essa emoção tem sido utilizada, quiçá deliberadamente, como estratégia de gestão. Os trabalhadores seguem, em grande medida, os ditames da gestão sobre a pausa, a jornada e o ritmo, recusando seus legítimos direitos, estabelecidos pelo TAC/2011 e consolidados pela NR-36. Igualmente, a negação de direitos recusa, sobretudo, a condição psicofísica e o sofrimento no seu teor físico ou psíquico. Destarte, os dados sobre saúde mental (SELIGMANN-SILVA et al., 2010) estimulam-nos a considerar que as práticas da gestão, ao burlarem os direitos e as ações provenientes do movimento social que visam promover a saúde dos trabalhadores, são vivenciadas por estes na mais profunda solidão. Parece que, deste modo, podemos entender que as iniciativas de organização das demandas coletivas são constantemente vencidas e solapadas, como pudemos vislumbrar no caso da assembleia de 30 de julho de 2012, em que os trabalhadores deixaram-se conduzir em fila e manipular pela gestão, que não queria o estado de greve. 


\section{"Medo": PALAVRA (DES)ENCANTADA}

Procuramos, por um lado, refletir sobre o significado profundo do medo, como palavra que provavelmente expressa determinadas situações vivenciadas por esse coletivo de trabalhadores. Por outro, tentamos iluminar tais prováveis vivências a partir de seu horizonte histórico. Assim, consideramos "medo" como uma palavra que pode revelar certa relação com o futuro como de "possibilidades mortas", evidenciada, sobretudo, pela corporeidade vivida como parte da máquina. Então, sob nosso olhar, "medo" e corpo máquina estão atravessados por relações de poder que estabelecem processos de dominação.

As investigações de Neli (2006), Sardá, Ruiz e Kirtschig (2009), Santos (2011), Dal Magro (2012) apresentam tanto as condições de trabalho quanto os aspectos relacionados aos distúrbios físicos e psíquicos dos trabalhadores de frigoríficos. Tais trabalhos são indicativos importantes de que o "medo" vivenciado pelos trabalhadores e algumas de suas dimensões, principalmente aquelas referentes à subserviência dos trabalhadores às diretrizes organizacionais da gestão, envolvem as diversas variáveis que compõem o processo de trabalho.

Neli (2006) refere, em seu estudo num frigorífico do Oeste do Paraná, que sintomas de distúrbios do sono ligam-se ao "medo" de perder o início do turno. Santos (2011) e Dal Magro (2012), no contexto do Oeste catarinense, mostram o "medo" de perder o emprego sob dois aspectos: um deles aparece como ameaça de demissão, mecanismo utilizado pelos gestores para o controle dos trabalhadores; e outro deles trata-se da demissão propriamente dita, como atitude dos gestores comumente avalizada pelo médico da empresa, que descarta o trabalhador doente que já não lhes é mais útil. Acrescenta-se a este último aspecto o medo de ser considerado um "mau" trabalhador por entrar em licença de saúde, acarretando a muitos trabalhadores, com dor, a permanência no trabalho. Ademais, há o medo de sofrer a repressão impingida pela gestão, que visa, por sua vez, desestabilizar a organização dos trabalhadores.

O "medo", em variados contextos de trabalho, tem sido discutido, principalmente, como medo de perder o emprego. Nossas análises sobre estudos recentes do campo da saúde mental e trabalho (SELIGMANN-SILVA et al., 2010) encontraram outro aspecto que pode ser decorrente da manipulação do medo como estratégia de gestão: trata-se do medo como sintoma que comporia as psicopatologias inerentes ao trabalho.

Para refletir sobre o "medo" e suas implicações nos contextos de trabalho, partimos do pressuposto de que o "medo" vivenciado, sendo uma emoção (SARTRE, 2002), está sempre relacionado a algo ou alguém. A vivência do "medo" implica as relações com o mundo, com o corpo, com o outro e com o tempo, que, por sua vez, são coextensivas umas às outras (MERLEAU-PONTY, 2006). Neste sentido, parece-nos importante sinalizar que o "medo" relaciona-se a aspectos do mundo que são, efetivamente, amedrontadores, tais como as consequências de estar-se submetido a ritmo acelerado, jornada extenuante, ruído persistente, frio constante etc. A demissão pressupõe aos trabalhadores a falta de salário, que 
implica falta da manutenção de condições mínimas que lhes assegurem a sobrevivência, conotando, da mesma forma, as dimensões do futuro que lhes são amedrontadoras. Igualmente, o ritmo acelerado faz vivenciar o corpo e seus limites sendo ultrapassados, sobretudo se dor estiver insistentemente presente, dessa maneira delineando-se as condições favoráveis para o adoecimento o que pode ser facilmente antecipado pelo trabalhador como seu futuro próximo. Por fim, necessitamos considerar a relação com os outros com os quais não se pode interagir, e a quem se ameaça e por quem se é ameaçado, em função da produção para alcançar a meta. Deste modo, a relação com o outro aparece como obstáculo, e sua dimensão fraterna fica muito reduzida se vislumbramos no horizonte de possibilidades a competição, a mentira e a traição.

No cotidiano do processo de trabalho, o "medo" é vivido como uma emoção enquanto vai sendo manipulado pelos mecanismos de gestão. Parece plausível a hipótese de que, ao longo do tempo, ele se apresente como sintoma constituinte de psicopatologias tais como a síndrome de Burnout, a síndrome do estresse pós-traumático, a depressão e a síndrome do pânico, correlacionadas aos processos de trabalho específicos (SELIGMANN-SILVA et al., 2010). Neste sentido, sob nossa ótica investigativa, o processo de trabalho pode ser entendido como categoria de análise de grande relevância na direção e na busca de desvelar tanto as mais diversas experiências psicológicas quanto os matizes do processo sócio-histórico que as envolvem. Por isso, convém considerar o processo de trabalho e sua organização como um conceito norteador e como objeto de diagnóstico e de intervenção, unificando e construindo o campo da saúde mental do trabalhador.

Tendo em vista que a organização do processo de trabalho envolve a produção e afeta a condição psicofísica dos trabalhadores, o seu controle é disputado, principalmente "[...] no que concerne às pausas, aos movimentos e aos tempos de realização das operações." (MERLO; LAPIS, 2007, p. 62). Desta forma, Minayo-Gomes e Lacaz (2005, p. 799) postulam que "[...] a análise dos processos de trabalho é uma ação teórico-prática potente, pois permite identificar as transformações necessárias a serem introduzidas nos locais e ambientes para a melhoria das condições de trabalho e saúde".

Portanto, são aspectos do mundo que precisam ser modificados a fim de que o "medo" como constituinte do sofrimento psíquico no trabalho seja superado. Consideramos, então, importante postular que são os elementos do processo de trabalho e de sua organização que precisam, urgentemente, ser reestruturados visando à saúde do ser humano na condição de trabalhador que faz parte de processos de trabalho específicos. E, ao mesmo tempo, trata-se de ponderar a história singular que se faz "[...] produtora de enigmas que retornam incessantemente e contribuem para o ordenamento das condutas sociais, por um lado; e que dão, por outro, um sentido àquilo que foi vivido." (LANCMAN; SZNELWAR, 2004, p. 243). Destarte, a relação entre sujeito e história pode auxiliar-nos na compreensão de tais experiências para desvelarmos ainda mais a relação entre o medo, a solidariedade e a resistência e averiguarmos seu desdobramento em sofrimento até constituir quadros psicopatológicos muito delimitados em função dos processos de trabalho. 


\section{Considerações Finais}

Demarcamos um contexto histórico que parece ser de dominação tanto das redes sociopolíticas que transcendem a fábrica quanto daquelas do seu cotidiano de funcionamento, por meio de gestão. A experiência histórica, em sua maioria alienada, é vivida individualmente, num ambiente hostil onde a solidão impera, e, em boa parte, por uma corporeidade afetada pela doença ocupacional e pelos acidentes de trabalho. Mediante tal contexto, um conjunto de forças representadas pela aliança entre setores do poder público e a organização política dos trabalhadores mobilizam um processo de resistência cujo auge é a eleição de um sindicato que prima pela saúde dos trabalhadores.

Neste contexto, pudemos entender, a partir dos dados reunidos, bem como das pesquisas que nos auxiliaram, que o medo está relacionado a uma experiência similar à da "perda da humanidade", a qual chamamos de "reificação". Esta experiência, sob nosso olhar, foi simbolizada pela analogia entre ser trabalhador e ser "máquina", o que sugere, concomitantemente, a relação com o futuro como de "possibilidades mortas".

Esta última experiência, isto é, da perda do futuro, reforça elementos da dinâmica que envolve a resistência, a solidariedade e o medo; assim como, a nosso ver, deve apresentar-se materializada no sintoma desenhando quadros psicopatológicos que têm sido recorrentes no âmbito do trabalho.

Por fim, foi plausível refletir sobre as indicações da recorrência do uso da palavra "medo". Ela nos sugeriu uma vivência a ser enfrentada e uma vivência manipulada pela organização do trabalho. Mas, sobretudo, apontou a necessidade de novas investigações sobre a sua relação com psicopatologias, que têm se tornado cada vez mais presentes nas pesquisas e experiências profissionais em diversas categorias ocupacionais. 


\section{REFERÊNCIAS}

ADORNO, T. Notas de Literatura I. São Paulo: Duas Cidades/34, 2003.

BENJAMIN, W. Magia e técnica, arte e política: ensaios sobre literatura e a história da cultura. São Paulo: Brasiliense, 1994.

BONDÍA, J. L. Notas sobre a experiência e o saber da experiência. Revista Brasileira de Educação, [online], n. 19, jan.-abr. 2002. Disponível em: <http:// anped.org.br/rbe/rbedigital/RBDE19/RBDE19_04_JORGE_LARROSA_ BONDIA.pdf > . Acesso em: 1 ago. 2013.

BRASIL. Ministério do Trabalho Emprego. Portaria MTE n. 555, de 18 de abril de 2013. Aprova a Norma Regulamentadora n. ${ }^{\circ} 36$ - Segurança e Saúde no Trabalho em Empresas de Abate e Processamento de Carnes e Derivados. Brasília: MTE, 2013.

BRASIL. Ministério Público do Trabalho. Termo de Ajuste de Conduta n. 01477. Procuradoria Regional do Trabalho da 12 Região, 2011. Brasília: MPT, 2011.

DAL MAGRO, M. L. P. Entre a saúde e a norma: a atenção à saúde dos trabalhadores das agroindústrias do oeste de Santa Catarina. 2012. Tese (Doutorado)-Universidade Federal de Santa Catarina, Florianópolis, 2012.

DEJOURS, C.; BÈGUE, F. Suicídio e trabalho: o que fazer? Brasília: Paralelo $15,2010$.

ESPÍNDOLA, J. C. As agroindústrias no Brasil: o caso Sadia. Chapecó: Grifos, 1999.

FOUCAULT, M. Os corpos dóceis. In: prisão. Petrópolis, RJ: Vozes, 1987a. p. 117-142.

FOUCAULT, M. Os recursos para o bom adestramento. In: punir: nascimento da prisão. Petrópolis, RJ: Vozes, 1987b. p. 143-161. . Vigiar e

HEIDEGGER, M. A caminho da linguagem. Petrópolis, RJ: Vozes, 2003.

LANCMAN, S.; SZNELWAR, L. Christophe Dejours: da psicopatologia à psicodinâmica do trabalho. Rio de Janeiro: Fiocruz; Brasília: Paralelo 15, 2004.

LANCMAN, S.; SZNELWAR, L. I. (Org.). Christophe Dejours: da psicopatologia à psicodinâmica do trabalho. Brasília: Paralelo 15, 2004.

MERLEAU-PONTY, M. Fenomenologia da Percepção. São Paulo: Martins Fontes, 2006. 
MERLEAU-PONTY, M. O visivel e o invisivel. São Paulo: Perspectiva, 2012.

MERLEAU-PONTY, M. Signos. São Paulo: Martins Fontes, 1991.

MERLO,A. R. C.; LAPIS, N. L. A saúde e os processos de trabalho no capitalismo: reflexões na interface entre a psicodinâmica do trabalho e a sociologia do trabalho. Psicologia \& Sociedade, Belo Horizonte, v. 19, n. 1, p. 61-68, jan./abr. 2007.

MYNAIO-GOMES, C.; LACAZ, F. A. C. Saúde do trabalhador: novas-velhas questões. Ciência e Saúde Coletiva, [S.1.], v. 10, n. 4, p. 797-807, 2005.

NELI, M. A. Reestruturação produtiva e saúde do trabalhador: um estudo com os trabalhadores da indústria avícola. 2006. Dissertação (Mestrado)-Universidade de São Paulo, Ribeirão Preto, 2006.

SANTOS, M. A. O Sofrimento dos trabalhadores da agroindústria Sadia S.A de Chapecó. 2011. Dissertação (Mestrado)-Universidade Federal de Santa Catarina, Florianópolis, 2011.

SARDÁ, S. E.; RUIZ, R. C.; KIRTSCHIG, G. Tutela jurídica da saúde dos empregados de frigoríficos: considerações dos serviços públicos. Acta Fisiátrica, [online], v. 16, n. 2, p. 59-65, 2009. Disponível em: <http://www.actafisiatrica. org.br/detalhe_artigo.asp?id=109>. Acesso em: 25 set. 2013.

SARTRE, J. P. A crítica da razão dialética. Petrópolis, RJ: Vozes, 2002.

SARTRE, J. P. O ser e o nada. Petrópolis, RJ: Vozes, 1997.

SELIGMANN-SILVA, E. et al. O mundo contemporâneo do trabalho e a saúde mental do trabalhador. Rev. bras. saúde ocup., São Paulo, v. 35, n. 122, dez. 2010. Disponível em: <http://www.scielo.br/scielo.php?script=sci_arttext\&pid=S0303$76572010000200002 \& \operatorname{lng}=e n \& n r m=i s o>$. Acesso em: 22 set. 2013.

SELIGMANN-SILVA, E. Trabalho e desgaste mental: o direito de ser dono de si mesmo. São Paulo: Cortez, 2011.

SILVEIRA, F. A.; FURLAN, R. Corpo e alma em Foucault: postulados para uma Metodologia da Psicologia. Psicologia USP, v. 14, n. 3, p. 171-194, 2003.

SITRACARNES. Boletins 12, 13, 16 e 19. Chapecó, 2012.

Recebido em: 30 de outubro de 2013

Aceito em: 21 de maio de 2014 
